\title{
Knowledge of Antenatal Mothers Regarding Human Milk Banking
}

\author{
Philomena Fernandes ${ }^{1}$, Sabitha Nayak ${ }^{2}$ \\ ${ }^{I}$ Department of $O B G(N)$, Nitte Usha Institute of Nursing Sciences, Paneer, Mangalore, ${ }^{2}$ Professor, Department of \\ $O B G(N)$, Nitte Usha Institute of Nursing Sciences, Paneer, Mangalore
}

\begin{abstract}
Introduction: Background: Breast milk is the perfect food and uniquely superior to, artificial baby milk. Giving a child breast milk from another woman is not a newer concept; wet nursing was a fairly common practice a few decades ago. Human milk banks are services which collect, screen, process and distribute donated breast milk. Current research evidences suggest that pasteurized donor human milk can provide many of the components and eliminate the risk of transmission of infectious agents.

Method: Quantitative research approach was adopted to assess the knowledge on Human Milk Banking; a structured knowledge questionnaire was given to 100 antenatal mothers. The study was conducted at Justice K.S Hegde charitable Hospital. Descriptive survey design was adopted to accomplish the objectives.

Results: Findings revealed that $52 \%$ of mothers had good knowledge and remaining mothers had an average knowledge. The 'p' value of age with regards to knowledge on human milk banking is 0.099 , whereas the ' $p$ ' value of parity is 0.718 . Meanwhile the ' $p$ ' value of family is 0.213 and that of religion is 0.428 . For education, occupation, income and any previous exposure with human milk banking the 'p' values were $0.284,0.082,0.104$ and 0.750 respectively. The above results shows that for all the demographic characteristics, the ' $p$ ' value is $>0.05$. Hence it was found that there was no significant association between knowledge of antenatal mothers with selected demographic variables.
\end{abstract}

Conclusion: Providing knowledge to antenatal mothers on human milk banking serve as an investment for the future needs. The nurse practitioner has a primary responsibility of enhancing the knowledge and developing positive attitude, towards utilization of human milk banking.

Keywords: Knowledge, Antenatal Mothers, Human Milk Banking, Information Booklet.

\section{Introduction}

Breast milk is the perfect food for human infants. It is markedly different from, and uniquely superior to, artificial baby milk ${ }^{1}$. Wet nursing was fairly common practice few decades ago. Human milk banks play an essential role by providing human milk to infants who would otherwise not be able to receive human milk. Human milk protects premature infants from necrotizing enter colitis and from sepsis, two devastating medical

\section{Corresponding author:}

Dr. Sabitha Nayak,

Professor, Department of OBG (N), Nitte Usha Institute of Nursing Sciences, Paneer, Mangalore.

E-mail: sabitha@nitte.edu.in conditions. Milk banks collect, screen, store, process, and distribute human milk. Donating women usually nurse their own infants and have a milk supply that exceeds their own infants' needs ${ }^{2}$. Breast milk is the main source of food for the baby, which is necessary for its growth and development ${ }^{3}$. Every mother looks forwards for a healthy baby. Breastfeeding also allows mother and baby to bond emotionally.

WHO Recommended exclusive breastfeeding for first 6months and continue till two years of age along with weaning4. In some instances the mother may pass away soon after delivering, mother maybe having infectious diseases or the mother is not able to produce sufficient milk. Unfortunately the baby may not get the mother's breast milk and thus the basic needs couldn't 
be meet. In such cases the human milk bank plays a vital role. The human milk bank is a service which collects, screens, crosses and dispenses human milk ${ }^{5}$.

\section{Background of the study}

The world's first human milk bank was founded in 1909 in Vienna, Austria6. After Vienna, the first human milk bank opened in the United States in the Boston Floating Hospital. In the 1960s, efforts in human milk bank faded due to advances in neonatal medical care and infant nutrition. Human milk banks are services which collect, screen, process and distribute donated breast milk. Recipients are generally ill and premature infants whose mothers are unable to breastfeed them. As survival rates for preterm infants improve, more attention is being focused on improving the quality of survival through optimal nutritional management. WHO and UNICEF, made a joint statement in 1980: "where it is not possible for the biological mother to breast feed, the first alternative, if available, should be the use of human milk from other sources 7 .

Breast milk that has been expressed, pasteurized and stored in sterilized conditions is safe and healthy for babies. The milk in the human milk bank is collected from donor mothers on the third day after giving birth, if they fulfill certain safety criteria that have been set by the hospital. The milk bank has one refrigerator, one sterilizer and two pasteurizers ${ }^{8}$. The steel containers are washed and sterilized in the sterilizer. The containers are then sent for collection of milk. The technician washes her hands, and labels the containers. The milk is pasteurized in the pasteurizer for half an hour at the prescribed temperature. A sample is taken and sent to microbiology department for testing for infections. After the report comes the milk is stored in the freezer at -20 degrees C. Milk thus collected can be stored for 3 to 6 months in prescribed conditions 9 .

Working mothers are more prevalent in today's world comparing with the ancient era. This brings a greater revolution in the life style of the people. So the women cannot concentrate on adequate nutrition to the child at the fullest. On the other hand women who are not able to breast fed their child because of the circumstances like diseases, infections or due to death of the mother soon after the delivery. At this point human milk banking is the better option ${ }^{10}$.
A study was conducted in South Australia by Lording R J in 2006.The study explored mothers knowledge towards human milk banks. Semi structured interview was conducted with 12 mothers who were breast feeding or have preterm babies or sick babies. Mothers of pre term infants would use a human milk bank only if they are ensured that milk was safe and appropriate for their babies $^{11}$.

A study conducted by Ahmet Karadag, Ramzan Ozdemir,Nuharrem Ak,Ali Ozer,Deryo Gumus Dogan and Ozlem Elkiran,Turkey, the study aims to determine the knowledge. They used descriptive cross sectional study on 1042 mothers who delivered at 2 different hospitals in Turkey. The result was almost half of the participating mothers (49.9\%) agreed to the establishment of alternative HMB. Only $7.75 \%$ of mothers expressed views in favour of HMB .Only $9.2 \%$ mothers were willing to donate their breast milk for HMB.33.9\% of mothers approved receiving milk from this type of $\mathrm{HMB}^{12}$.

A study was conducted by Derya Kaya Senol, Ergul Aslan in Turkey. The study was to determine opinion of woman about human milk donation and HMB. They used cross sectional descriptive design on 231 married women who gave birth at least once. Data was collected using questionnaire and face to face interview, result was half of the women found human milk donation acceptable and $58 \%$ of the women stated they wanted to donate their milk, $45 \%$ women refused since it was against religious rule and $23.6 \%$ since it was having risk for infectious disease ${ }^{13}$.

A study conducted in India (2006) has been providing mother's milk to new born babies. The human milk banking at Sion Hospital caters new born and premature babies whose mother's do not lactate. There are at least 8000 babies born every year, in that 20-35\% of these cases, direct breast feeding becomes impossible where human milk bank becomes a support system ${ }^{14}$.

A study conducted in Perth; the expression of breast wil allow of the mother to be away intermittently from her infant while continuing to breast feed. Total 587 mothers were taken, out of which $93 \%$ of mothers though returning from work were exclusively giving breast milk with the help of expressed breast milk whereas $7 \%$ discontinued with the reason of less breast milk ${ }^{15}$. 
A study conducted at Tumkur City to assess the effectiveness of information booklet on knowledge and practices of expressed breast milk among 30 postnatal mothers. The result was that $71 \%$ of mothers were found to get effective information regarding expressed breast $\operatorname{milk}^{16}$.

\section{Need for the study}

Working mothers are more prevalent in today's world comparing with the ancient era. This brings a greater revolution in the life style. Women who are not able to breast fed their child because of the circumstances like diseases, infections or due to death of the mother soon after the delivery. At this point human milk banking is the better option.

When maternal breast milk is not available in sufficient quantity, donor breast milk is recommended as an alternate source of nutrition, particularly in preterm and other high-risk infants.

It is universally accepted that breast milk is the optimum exclusive source of nutrition for the first six months of life. Despite advances in infant formulas, human breast milk provides a bioactive matrix of benefits that cannot be replicated by any other source of nutrition. When the mother's own milk is unavailable for the sick, hospitalized newborn, pasteurized human donor breast milk should be made available as an alternative feeding choice.

Promoting health is the role of an advanced nurse practitioner in improving and maintaining the health and well-being of newborn babies. Educating and empowering the antenatal mothers to integrate healthy practices is an important task in the hand of health care providers. Therefore, the investigator was interested in preparing an information booklet on human milk banking.

\section{Objectives}

1. To assess the knowledge of antenatal mothers regarding human milk banking.

2. To find an association between knowledge of antenatal mothers on milk banking with selected demographic variables.

3. To prepare an information booklet on human milk banking

\section{Protection of human subject}

1. Ethical clearance was obtained from Institutional ethics committee after presenting the research proposal.

2. To conduct research study, the investigator obtained written permission from Justice K. S Hegde Hospital. Informed consent obtained and confidentiality was assured.

\section{Research methodology}

Quantitative research approach was adopted in the study. Convenient sampling technique was used to select 100 antenatal mothers from Justice K. S. Hegde charitable hospital. Descriptive survey design was adopted in order to accomplish the objectives.

The data collection instruments were demographic proforma and a structured knowledge questionnaire on human milk banking consists of 28 questions. The value of reliability of tool was obtained through Cronbach's Alpha using SPSS statistics and it is found to be reliable with the score 0.76 . The data were collected from $11 / 1 / 2019$ to $19 / 2 / 19$. And the data were entered systematically in the SPSS for data analysis.

\section{Development of information booklet}

On interpretation of results it was found that only few antenatal mothers had some knowledge on human milk banking. To spread the awareness about human milk banking an information booklet was developed that provided basic information on human milk banking and its need.

\section{Result}

Data were analyzed using descriptive and inferential statistics with the help of frequency and percentage. Chi square test have been applied to find the association. Data analysis under the following sections

Section I: Description of demographic proforma

Section II: Knowledge on human milk banking

Section III: Association between knowledge of antenatal mothers with selected demographic variables. 
SECTION I: DESCRIPTION OF DEMOGRAPHIC CHARACTERISTIC

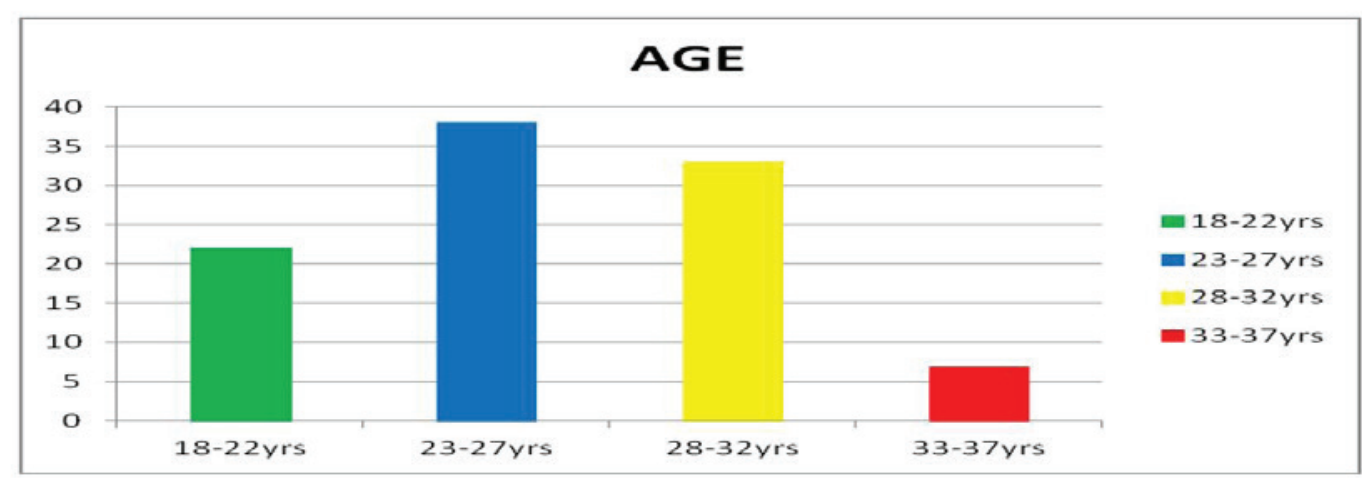

Figure 2: Distribution of age

Fig 1: Distribution of Age

The graphical representation depicts that out of 100 participants 38 of them were in the age group of 23-27 years and 33 of them were in the age group of 28-32 years, 22 were in the age group of 18-22 years and only 7 of them were in the age group of 33-37 years.

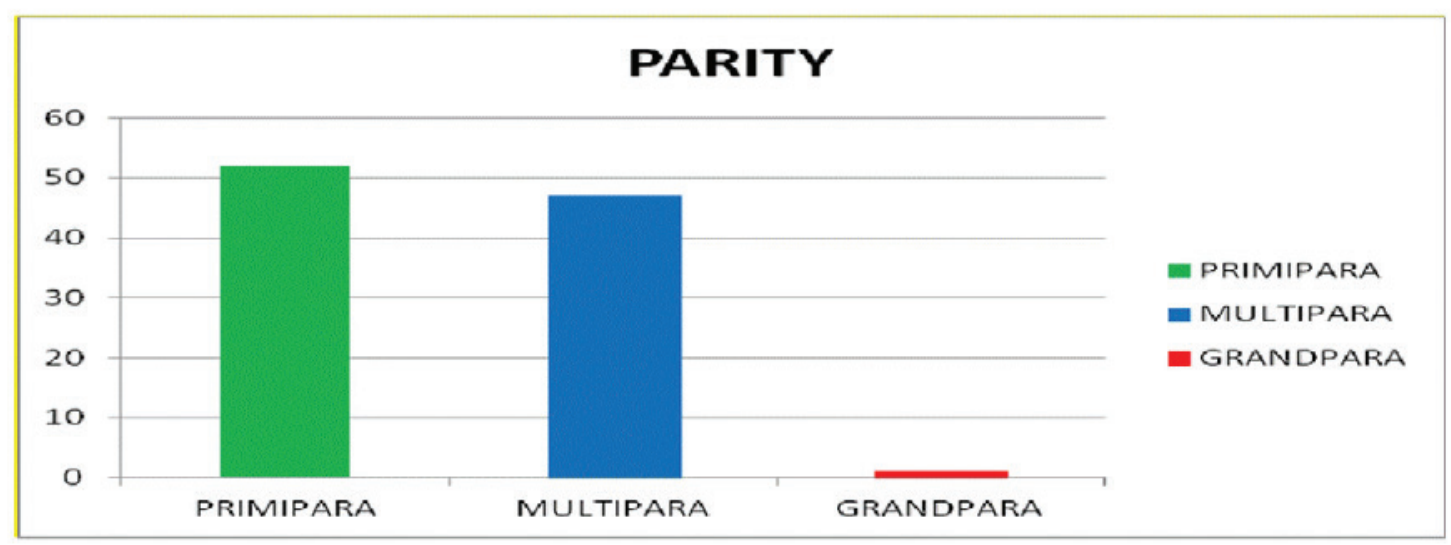

Figure 3: Distribution of Parity

Fig 2: Distribution of Parity

The bar diagram shows that 52 of them were primipara, 47 of them were multipara and only 1 belongs to grand multipara 


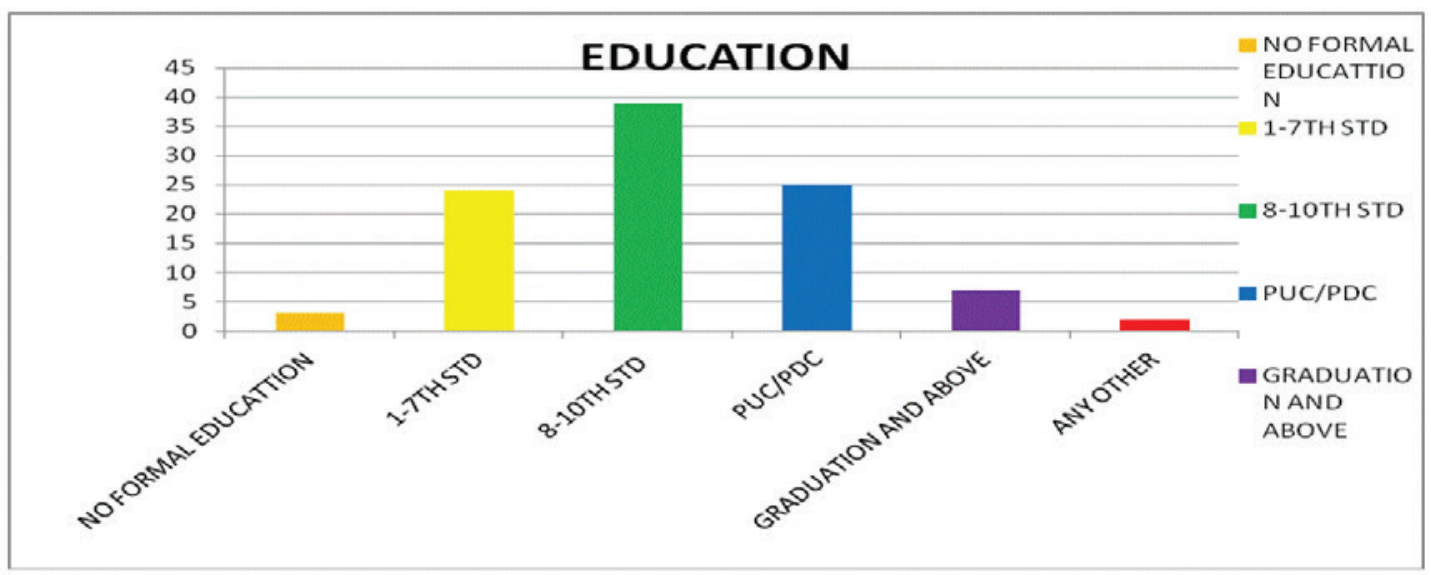

Figure 4: Educational Status of antenatal mothers

Fig 3: Educational status of antenatal mothers

The bar diagram shows, out of total participants 3 of them were having no formal education, 24 of them had education between 1-7th standard, 39 of them educated in between 8-10th standard, 25 of them studied till PUC and 7 of them were graduates and only 2 of them were not belonging to any of these categories.

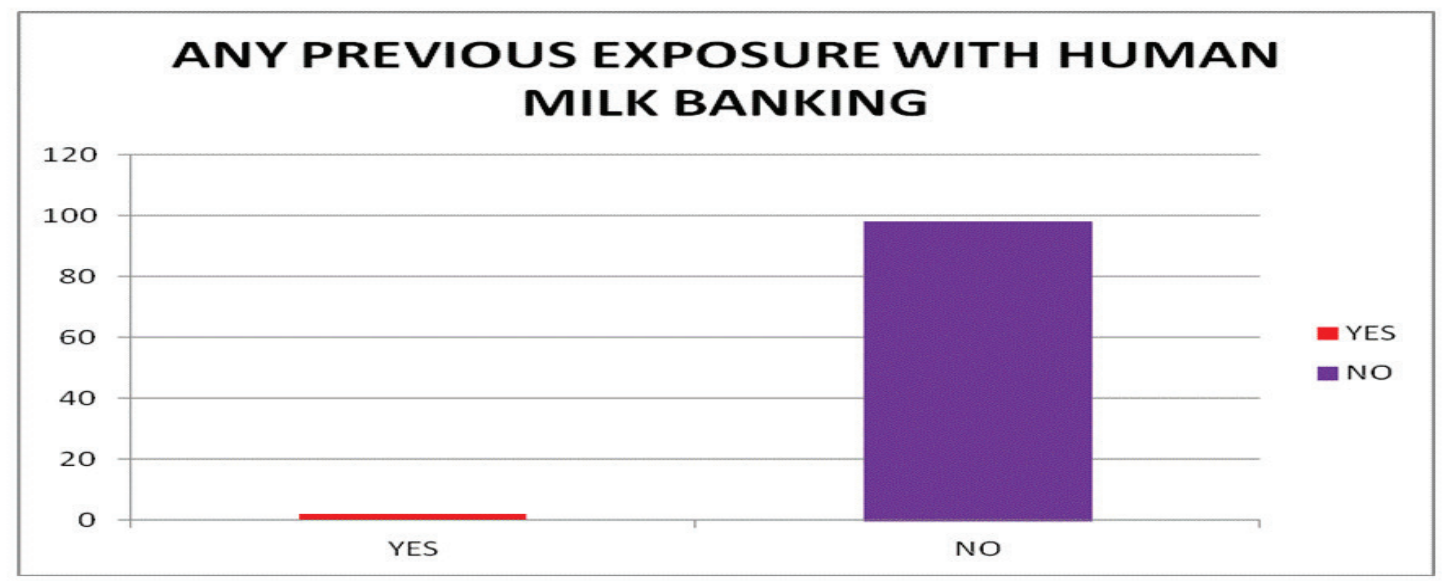

Figure 5: previous exposure to human Milk banking

Fig 4: Previous exposure to human Milk banking

Bar diagram shows that, out of 100 participants $98 \%$ of them were not having any previous exposure with human milk banking and only $2 \%$ of them were having a vague knowledge regarding human milk banking.

Section II: Knowledge on human milk banking 


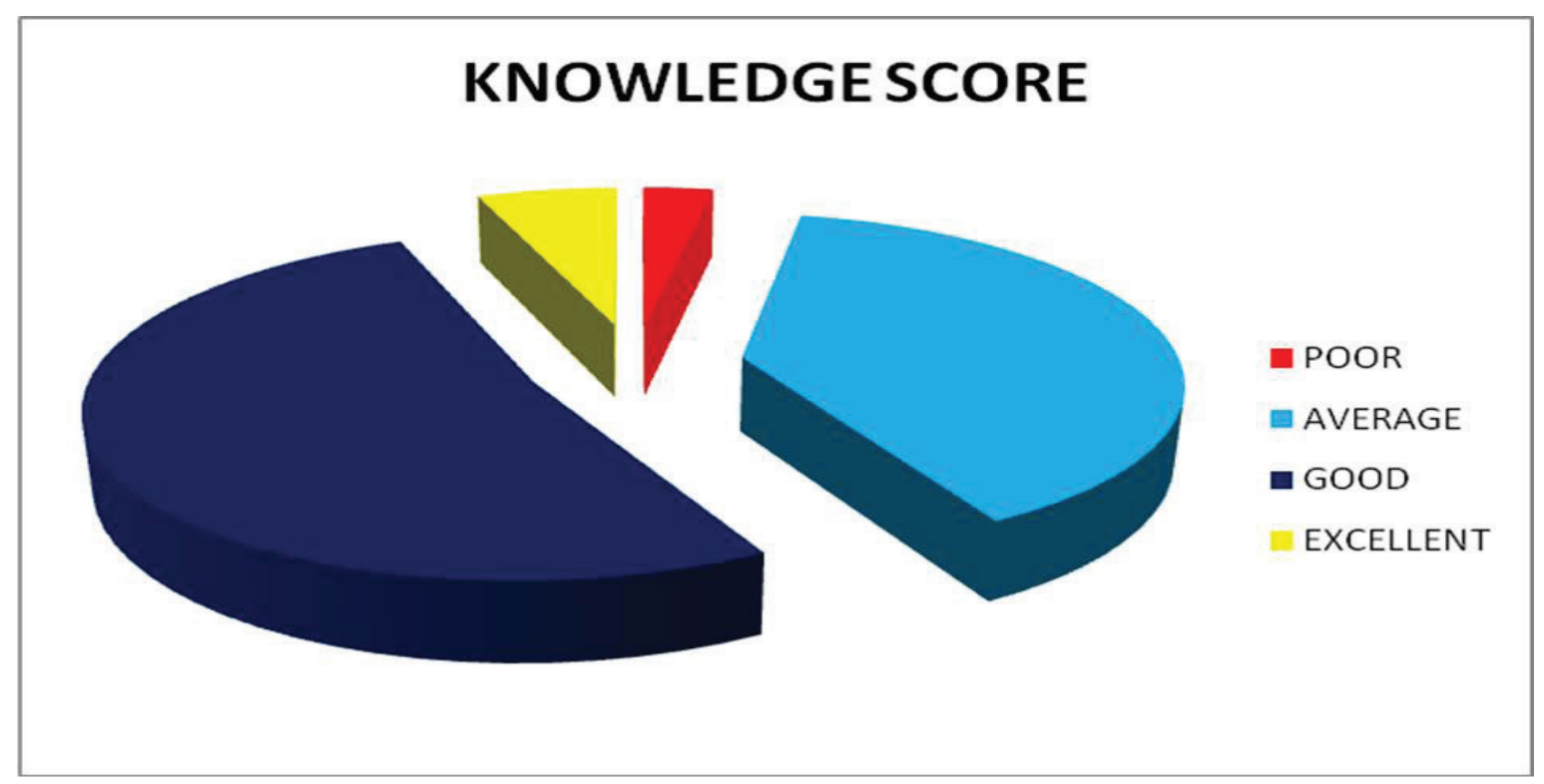

Figure 6: Level of knowledge on Human Milk Banking

Fig 5: Level of Knowledge on Human Milk Banking

Pie diagram depicts majority of the participants (52\%) were having good knowledge regarding human milk banking following 39\% of the antenatal mothers were having average knowledge, a few (6\%) were having excellent knowledge and only $3 \%$ were having poor knowledge on human

Section III: Association between knowledge of antenatal mothers with selected demographic variables.

The results of the study shows that the 'P' value of chi square test for association between knowledge on human milk banking with demographic variables such as age is 0.099 , whereas the ' $p$ ' value of parity is 0.718 . Meanwhile the 'p' value of family is 0.213 and that of religion is 0.428 . For education, occupation, income and any previous exposure with human milk banking the ' $p$ ' values were $0.284,0.082,0.104$ and 0.750 respectively. The table mentioned above shows that for all the demographic characteristics, the $p$ value is $>0.05$. Hence it was found that there was no significant association between knowledge of antenatal mothers with selected demographic variables.

\section{Discussion}

Description on demographic variables
Majority of the subjects (38\%) belong to $23-27$ years of age group.

Most of the mothers (52\%) were belonging to primipara.

It is evident that majority of mothers $(65 \%)$ belong to nuclear family.

More number of the antenatal mothers (64\%) belongs to Hindu religion.

The greater $(39 \%)$ were having education between 8-10th standard.

More than half of them (56\%) having income of $<10000$.

Two of them had received the information about human milk banking from internet. In a study on 60 working mothers those who are working in selected urban areas most of the mothers were in the age group of 18-35years.Majority of the study population were Hindus (85\%), housewives (77\%), living in nuclear family set-up (66\%).

Description on knowledge score of antenatal mothers. 
The findings of the study revealed that $52 \%$ of antenatal mothers had good knowledge and 39\% of them had average knowledge on milk banking. Whereas only $6 \%$ of the mothers had excellent knowledge and 3 of them had poor knowledge.

The above findings were supported by the study conducted by Sangeetha et.al in selected hospitals to assess the knowledge and attitude regarding donating milk to the human milk bank. This study consisted of 60 postnatal mothers of selected hospital. Results shows that majority of the samples were having adequate knowledge. $78.33 \%$ of the samples had excellent level of knowledge score and $21.67 \%$ had good knowledge score.

\section{Conclusion}

Change is the end result of all through Learning 17.

Artificial formula feeds cannot supply broad benefits of human milk. The most suitable way to acquire is only the Human Milk Banking. A large number of literatures strongly suggest that the antenatal mothers have poor knowledge on Human Milk Banking. Health education is one of the cost effective means that can be adopted to educate the antenatal mothers regarding human milk banking will help them in times of need, which can save lives.

Recommendations for future research:

A comparative study can be done in both antenatal and postnatal mothers to assess the knowledge regarding human milk banking.

\section{Acknowledgment}

The authors deeply acknowledge the antenatal mothers for their participation in the study.

\section{Conflict of Interest: Nil}

Source of Funding: Self

\section{References}

1. Gribble KD. Mechanisms behind breast milk's protection against, and artificial baby milk's facilitation of, diarrheal illness. Breastfeeding Review. 2011 Aug; 19(2):19.

2. Haiden N, Ziegler EE. Human milk banking. Annals of Nutrition and Metabolism. 2016; 69(Suppl. 2):715.

3. Gartner LM, Morton J, Lawrence RA, Naylor AJ, O'Hare D, Schanler RJ, Eidelman AI. Breastfeeding and the use of human milk. Pediatrics. 2005 Feb; 115(2):496- 506 .

4. Binns CW, Lee MK. Exclusive breastfeeding for six months: the WHO six months recommendation in the Asia Pacific Region. Asia Pacific journal of clinical nutrition. 2014 Sep 23; 23(3):344-50.

5. Centre for Clinical Practice at NICE (UK. Donor breast milk banks: The operation of donor milk bank services.

6. Haiden N, Ziegler EE. Human milk banking. Annals of Nutrition and Metabolism. 2016; 69(Suppl. 2):715.

7. World Health Organization. Reduction of maternal mortality: a joint WHO/UNFPA/UNICEF/World Bank statement.

8. Pardou A, Serruys E, Mascart-Lemone F, Dramaix M, Vis HL. Human milk banking: influence of storage processes and of bacterial contamination on some milk constituents. Neonatology. 1994; 65(5):302-9.

9. Michaelsen KF, Skafte L, Badsberg JH, and Jørgensen M. Variation in macronutrients in human bank milk: influencing factors and implications for human milk banking. Journal of paediatric gastroenterology and nutrition. 1990 Aug; 11(2):229-39.

10. Björkstén $B$, Burman LG, De Château $P$, Fredrikzon BO, Gothefors L, Hernell O. Collecting and banking human milk: to heat or not to heat? $\mathrm{Br}$ Med J. 1980 Sep 20; 281(6243):765-9.

11. Lording RJ. A review of human milk banking and public health policy in Australia. Breastfeeding Review. 2006 Nov; 14(3):21.

12. Ahmet Karadag, Ramzan Ozeemir, Nuharrem Ak, Ali Ozer, Deryo Gumus Dogan, Ozlem Elkiran. Breast-feeding knowledge and practices among mothers in Manisa, Turkey. Midwifery. 2009 Dec 1; 25(6):e19-32.

13. Kilinçkaya A. A study to determine the opinion of woman about human milk donation and human milk banking in turkey-III (2004-2013). Şarkiyat Mecmuas1. (27):95-130.

14. Faircloth $\mathrm{C}$. Militant. Attachment parenting and 
intensive motherhood in the UK and France. Berghahn Books; 2013 Mar 1.

15. Tohotoa J, Maycock B, Hauck YL, Howat P, Burns S, Binns CW. Dads make a difference: an exploratory study of paternal support for breastfeeding in Perth, Western Australia. International breastfeeding journal. 2009 Dec; 4(1):15.
16. Paliwal H. A descriptive study to assess the effectiveness of information booklet on knowledge and practices of expressed breast milk among 30 postnatal mothers in selected hospitals at Tumkur"'(Doctoral dissertation).

17. Leamnson R. Learning as biological brain change. Change: The magazine of higher learning. 2000 Nov 1; 32(6):34-40. 